\title{
FRACTOGRAPHIC ANALYSIS OF THE ALUMINUM MATRIX COMPOSITE PREPARED BY ACCUMULATIVE ROLL BONDING
}

\author{
Ivana Cvijović-Alagić *, Vesna Maksimović, Milan T. Jovanović \\ Center of Excellence „CEXTREME-LAB“, Vinča Institute of Nuclear Sciences - \\ National Institute of the Republic of Serbia, University of Belgrade, Mike Petrovića \\ Alasa 12-14, 11001 Belgrade, Serbia
}

Received 05.10.2020

Accepted 08.10.2020

\begin{abstract}
Recent research in the material science field is focused on the easy-to-apply and cost-effective production of the structural components with enhanced mechanical properties. As an answer to these new trends in the present study, the inexpensive household aluminum foils are used to produce the multilayer aluminum matrix composite. The aluminum matrix composites are manufactured by hot-rolling of the sandwiched foils and afterward subjected to microstructural characterization and mechanical testing. Analysis of the produced composite microstructure and fracture surface obtained after tensile testing was performed using the scanning electron microscopy (SEM). The qualitative fractographic analysis revealed that the ductile fracture features prevail in the overall fracture mode of the investigated multilayer composite, while the quantitative fractographic investigation allowed more detailed insight into the composite failure process and depicted critical parameters that led to the composite failure.
\end{abstract}

Keywords: Aluminum foils; Multilayer composite; ARB; Tensile testing; Fractographic analysis; Electron microscopy.

\section{Introduction}

Modern research trends in the field of material science and especially in the field of metallic materials for structural applications are focused on the innovative, costeffective production solutions for the obtainment of structural materials with enhanced mechanical properties. Metal matrix multilayer composites are singled out as materials that offer enhanced mechanical, thermal, electrical, and magnetic properties suitable for numerous structural applications [1-2]. Since aluminum is a lightweight metal, the usage of aluminum in fuel and energy-consuming applications is desirable. However, its utilization is quite limited in structural components in which high modulus and strength 
are required [3]. Due to their low density and good corrosion resistance, the aluminum alloys are considered good candidates as a matrix material in the modern metal matrix composites perceived for aeronautical, automotive, and military applications [3-6].

During the years, a significant number of production and processing procedures were proposed for the attainment of multilayer metal matrix composites [7,8]. However, the accumulative roll bonding (ARB) is identified as an easy-to-apply processing procedure for the production of multilayer composites in the form of bulk, which can serve as structural materials in highly demanding exploitation conditions $[6,9,10]$. This severe plastic deformation method is based on repeated folding and rolling of two or more metallic sheets stacked in the form of packages and allows the production of composites with ultra-fine grains and diverse interface structures [6,11]. Roll bonding of the metallic sheets, as the most significant stage in this process, plays a crucial role in the obtainment of the desired properties of the produced composites [5]. In their research, Alizadeh et al. [12] used the repeated roll-bonding (RRB) and the continual annealing roll bonding (CAR) process to eliminate the effects of work hardening by annealing the investigated material between each of the rolling passes. This procedure allowed the introduction of higher plastic deformation to the treated material, and in that way, the achievement of even stronger bonding of the layers in the produced multilayer composite can be accomplished.

Having all this in mind, the aim of the present research was to propose a costeffective production procedure for the obtainment of aluminum matrix composite with enhanced mechanical properties. Usage of the easily attainable and inexpensive materials was foreseen as a good starting ground for the production of the inexpensive composite, while the easy-to-apply production route, such as the ARB process, was utilized to secure the obtainment of the structural material with the desired characteristics.

\section{Experimental work}

For this investigation, the $17 \mu \mathrm{m}$ thick household aluminum foils designated as 8011A-O aluminum and supplied by Jiangsu Shenzhou Aluminum Industry Co. Ltd., China, were used as raw materials for the production of the multilayer composite. The foils chemical composition is given in Table 1 as it was obtained from the manufacturer.

Table 1. Chemical composition of the aluminum foils (in mass\%).

\begin{tabular}{llllll}
\hline $\mathrm{Si}$ & $\mathrm{Fe}$ & $\mathrm{Cu}$ & $\mathrm{Mn}$ & $\mathrm{Ti}$ & $\mathrm{Al}$ \\
\hline 0.5 & 0.68 & 0.024 & 0.01 & 0.009 & Balk \\
\hline
\end{tabular}

The as-received aluminum foils were cut into the $25 \mathrm{~mm} \times 70 \mathrm{~mm}$ strips, and 100 foil-strips were stacked into one package prior to the ARB processing. To prevent the dismount of the foil-strips package, wider aluminum foil was used for the package wrapping. Afterward, the aluminum foils were subjected to the binding process, which included alternate annealing and hot-rolling sequences. Annealing of the aluminum foils was conducted in air at $500{ }^{\circ} \mathrm{C}$ using the laboratory furnace, while for the hot-rolling of the aluminum foils, the rolling mill supplied by Albert Mann Engineering Co. Ltd., UK, was used, and the temperature of the rolls was maintained at $250{ }^{\circ} \mathrm{C}$. The duration of the initial annealing sequence was $2 \mathrm{~h}$, the final annealing sequence lasted for $1 \mathrm{~h}$, while two intermediate annealing sequences were undertaken for $15 \mathrm{~min}$. Similarly, the hot-rolling process was undertaken in four sequences where every single sequence was conducted in 
three hot-rolling passes resulting in the total amount of the foil-strips package hot deformation of $70 \%$ (Fig. 1). The ARB process-induced strong mutual bonding of aluminum foils and obtained multilayer composite was compact and sound without the indication of the surface peeling or layers detachment.

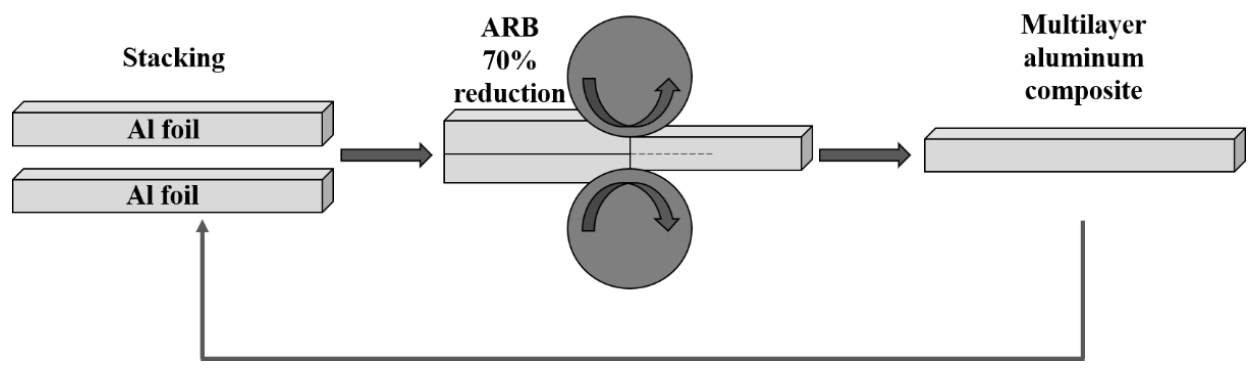

Fig. 1. Schematic overview of the ARB process for the multilayer aluminum matrix composite production.

To investigate the produced multilayer composite microstructure, the specimens were cut and prepared according to standard metallographic technique (grounding with $\mathrm{SiC}$ papers, polishing and etching in a $100 \mathrm{~mL} \mathrm{H}_{3} \mathrm{PO}_{4}+90 \mathrm{~mL} \mathrm{H}_{2} \mathrm{SO}_{4}$ solution). The microstructural characterization was performed using the JEOL Camscan FEG30 scanning electron microscope (SEM) at the accelerating voltage of $20 \mathrm{keV}$ (Fig. 2a). For the tensile testing, the microtensile specimens (Fig. 2b) were cut from the produced composite and investigated according to the ASTM D 1708 standard test method.

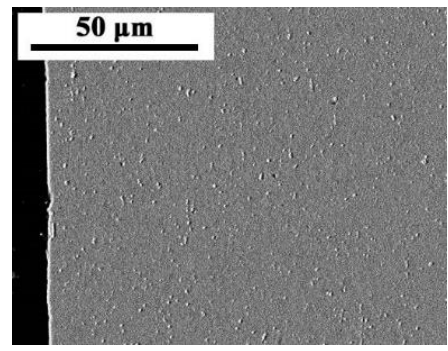

(a)

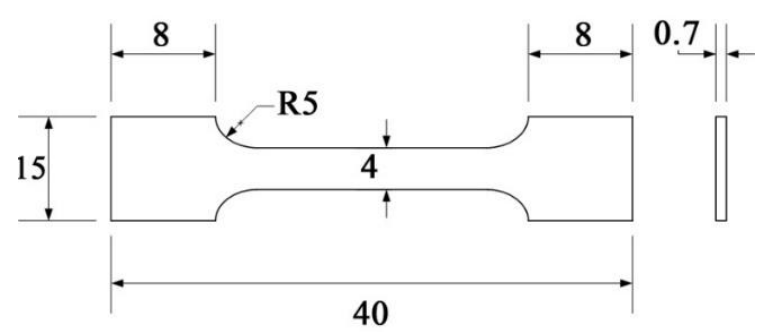

(b)

Fig. 2. (a) SEM micrograph of the multilayer composite and (b) schematic representation of the microtensile specimens' dimensions.

Tensile tests were conducted in quintuplicate at room temperature using a universal Instron TT-CM-L testing machine, as it was reported earlier [6]. The fractographic analysis was undertaken after the tensile testing using the JEOL JSM 5800LV SEM at the accelerating voltage of $25 \mathrm{keV}$. The fracture surface morphology was examined in the central region of the fractured microtensile specimen. For quantitative fractographic investigations, the metallographic sections oriented perpendicular to an average fracture plane containing the fracture profile line were prepared by grinding with $\mathrm{SiC}$ papers to 
2000 grit and polished with $3 \mu \mathrm{m}$ diamond suspension. A set of the SEM micrographs was recorded on these sections and analyzed using an image analyzer.

\section{Results and discussion}

As a result of the ARB processing, the final thickness of the obtained multilayer composite was $0.7 \mathrm{~mm}$. The SEM cross-sectional analysis indicated strong mutual bonding of foils. The interfaces between the individual foils cannot be noticed in the aspolished condition, while the absence of gaps and pores at the foils boundaries is evident. However, after the etching of the samples, a few coarser particles can be observed at the foil's interfaces (see Fig. 2a). Investigations conducted to identify the observed particles are presented in our previous work [6] and indicate that their chemical composition is similar to the intermetallic $\alpha$-AlFeSi phase [13].

Qualitative fractographic examinations revealed the presence of dimples and microvoids on the composite tensile fracture surface (Figs. 3a and 3b).

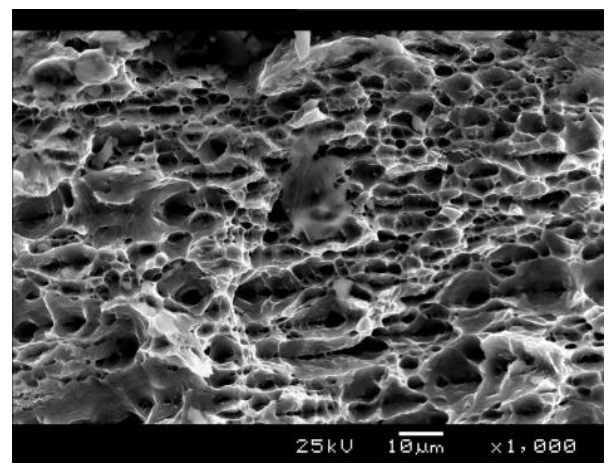

(a)

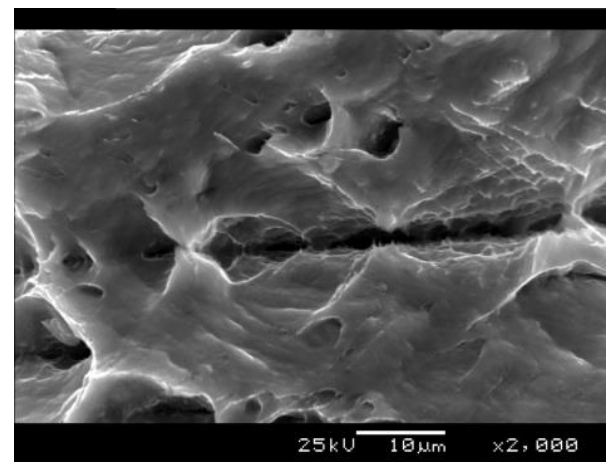

(c)

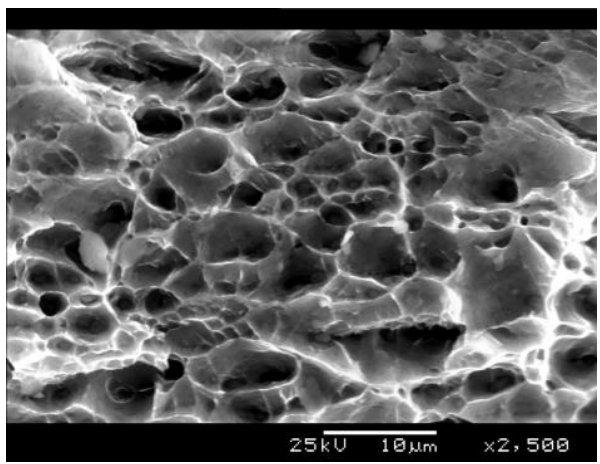

(b)

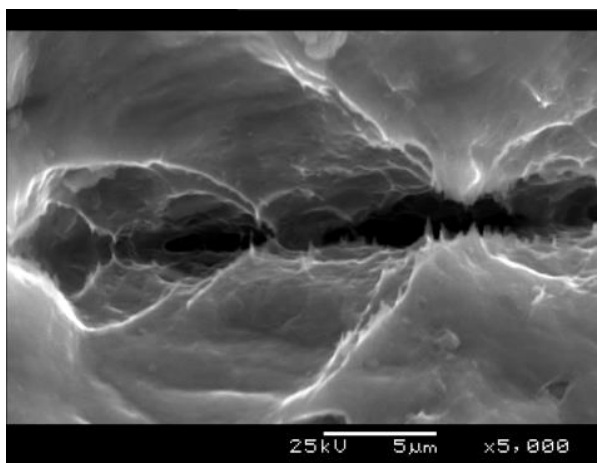

(d)

Fig. 3. SEM micrographs of the multilayer composite fracture surface.

Coalescence of microvoids and the presence of coarse and fine dimples indicate that the ductile fracture mode prevails in the overall fracture mechanism. Moreover, from the SEM micrographs, one can observe that the majority of dimples are elliptic in shape. This leads to the conclusion that the shear stress was present during the fracture causing 
in that way the stretching of dimples before the fracture. Due to the presence of the described fracture features, it can be concluded that the overall fracture mode is a shear ductile fracture. Even though the signs of delamination are not easily noticeable, straight cracks observed at higher magnification (Figs. 3c and 3d) are probably caused by the incomplete bonding of the two adjacent foils, which resulted in the rupture appearance. However, the foils delamination appears to be sporadic and does not significantly contribute to the overall fracture process.

Quantitative fractographic examinations are used to get a more detailed insight into the multilayer composite failure mode. Regarding that, the quantitative aspect of the geometric characteristics of the fracture surface topography is investigated, and corresponding parameters are determined (Fig. 4).
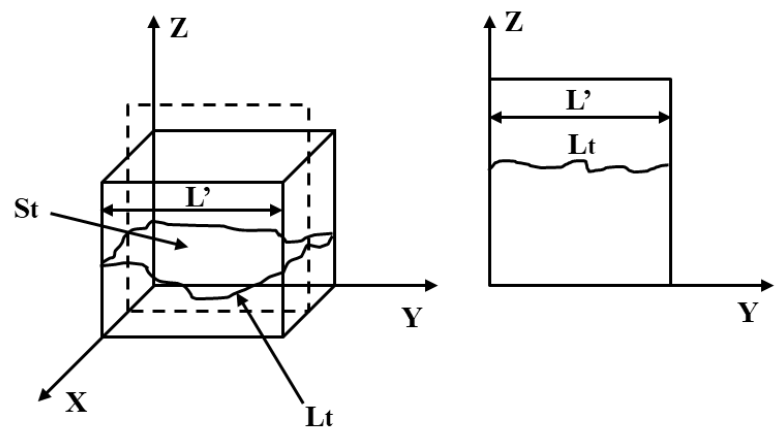

Fig. 4. Schematic overview of the fracture surface, the relative orientation of the sectioning plane, and the corresponding section fracture profile.

Namely, a set of the SEM micrographs recorded along the fracture profile line were used to attain the continuous fracture profile presented in Fig. 5 and to obtain the length of a generated fracture profile, $L_{t}$, and the length of a generated fracture profile projected on a line perpendicular to the vertical axis, $L^{\prime}$. These data were afterward used to determine the linear roughness parameter, $R_{L}$, and the surface roughness parameter, $R_{S}$, as the quantitative fractographic parameters. The profile roughness parameter can be calculated as the total profile length, and the total profile projected length ratio according to the Eq. 1 [14]:

$$
R_{L}=\frac{L_{t}}{L^{\prime}}
$$

The fracture surface roughness parameter, representing the ratio of the true fracture surface area and the fracture surface area projected on the perpendicular plane, was also calculated. For that purpose, several linear models are proposed in the literature and in the present study a model used for a partially oriented dimpled fracture surface [15] was utilized as follows:

$$
R_{S}=\frac{4}{\pi}\left(R_{L}-1\right)+1
$$




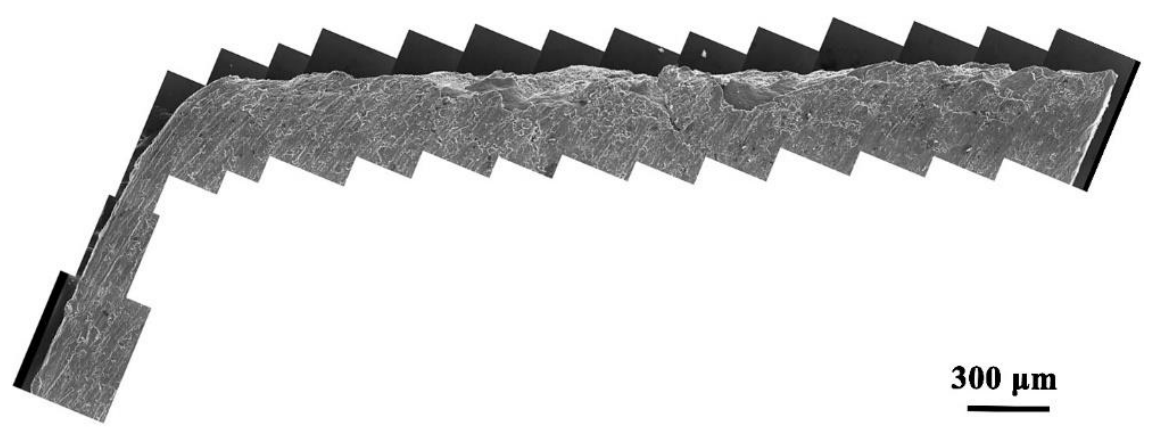

Fig. 5. SEM micrographs showing the fracture profile of the multilayer composite after the tensile testing.

Previous research conducted in this field indicates that the material with higher toughness values is characterized by the higher values of linear and surface roughness [16]. Calculated $R_{L}$ and $R_{S}$ values for the investigated multilayer composite are $1.46 \pm 0.01$ and $1.59 \pm 0.15$, respectively. These values of the quantitative fractographic parameters correspond to the profile line development degree characteristic to the ductile fracture mode.

According to the available data, the as-received 8011A-O aluminum foils are characterized by the hardness value of $25 \mathrm{HV}$ and show the yield strength $\left(\sigma_{0.2}\right)$ of $36 \mathrm{MPa}$ and the ultimate tensile strength $\left(\sigma_{T}\right)$ of $110 \mathrm{MPa}$, while the modulus of elasticity $(E)$ of the as-received 8011A-O aluminum foils is reported as $71 \mathrm{GPa}[6,17]$. On the other hand, the tensile testing of the produced multilayer composite showed that the ARB processing led to the moderate increase of the modulus of elasticity to a value of $75 \mathrm{GPa}$ and increased of the yield strength and the ultimate tensile strength to values of $90 \mathrm{MPa}$ and $115 \mathrm{MPa}$, respectively. Since the fracture toughness scales with the square root of the elastic modulus in the case of the ductile fracture mode [18], it can be assumed that material with a higher $E$ value shows higher fracture toughness and accordingly higher values of linear and surface roughness. Higher values of the quantitative fractographic parameters indicate that the length of a generated fracture profile, $L_{t}$, is somewhat increased in the case of the multilayer composite in comparison to the as-received 8011A$\mathrm{O}$ aluminum foils and accordingly suggest the higher degree of the profile line development corresponding to the appearance of the multimechanistic nature of the fracture [16]. Having all that in mind, it can be concluded that the ARB process, used for the obtainment of the multilayer composite, leads to the increase of the ductile fracture mode contribution to the overall fracture mechanism.

\section{Conclusion}

The research findings of the present study showed that the ARB process can be successfully introduced as a cost-effective procedure for the production of compact and sound inexpensive multilayer composite with improved mechanical characteristics. Multilayer composite attained by the ARB processing showed improved tensile properties compared with the properties reported for the pure aluminum foils which are used for the aluminum matrix composite production. Fractographic examination, conducted after the tensile testing, revealed that the shear ductile fracture is the overall fracture mode in the 
attained aluminum matrix multilayer composite. Signs of the composite delamination are sporadic and do not significantly contribute to the overall fracture process.

\section{Acknowledgements}

This work was financially supported by the Ministry of Education, Science and Technological Development of the Republic of Serbia through the fundamental national research projects. Authors would also like to acknowledge the help of Dr. Nenad Ilic during the production and investigation of the multilayer aluminum matrix composite.

\section{References}

[1] A. Misra, J.P. Hirth, R.G. Hoagland: Acta Mater, 53 (2005) 4817--4824.

[2] A. Giguere, N.H. Hai, N. Dempsey, D. Givord: J Magn Magn Mater, 242-245 (2002) 581-584.

[3] R. Jamaati, M.R. Toroghinejad: Mat Sci Eng A-Struct, 527 (2010) 4146-4151.

[4] S.V. Kamat, J.P. Hirth, R. Mehrabian: Acta Metall Mater, 37 (1989) 2395-2402.

[5] R. Yousefian, E. Emadoddin, S. Baharnezhad: Rev Adv Mater Sci, 55 (2018) 1 11.

[6] M.T. Jovanović, N. Ilić, I. Cvijović-Alagić, V. Maksimović, S. Zec: Trans Nonferrous Met Soc China, 27 (2017) 1907-1919.

[7] H.N.G. Wadley, L.M. Hsiung, R.L. Lankey: Compos Eng, 5 (1995) 935-940.

[8] D.M.A. Nabi Rahni, P.T. Tang, P. Leisner: Nanotechnology, 7 (1996) 134-143.

[9] P.J. Hsieh, Y.P. Hung, J.C. Huang: Scripta Mater, 49 (2003) 173-178.

[10] L. Battezzati, C. Antonione, F. Fracchia: Intermetallics, 3 (1995) 67-71.

[11] Y. Saito, H. Utsunomiya, N. Tsuj, T. Sakai: Acta Mater, 47 (1999) 579-583.

[12] M. Alizadeh, M. Paydar, M. Alizadeh, M.H. Paydar: J Alloys Compd, 477 (2009) 811-816.

[13] H.W. Kim, S.B. Kang, N. Tsuji, Y. Minamino: Acta Mater, 53 (2005) 1737-1749.

[14] S.D. Antolovich, A.M. Gokhale, C. Bathias, In: Quantitative Methods in Fractography. Eds: B.M. Strauss, S.K. Putatunda, ASTM, Philadelphia, PA, 1990, 3-25.

[15] E.E. Underwood, K. Banerji: ASM Handbook vol. 12 - Fractography, $9^{\text {th }}$ edition, ASM International, Metals Park, OH, 1999, 193-210.

[16] Z. Cvijović, M. Vratnica, I. Cvijović-Alagić: Int J Damage Mech, 20 (2011) 179193.

[17] Material Properties Database, https://www.makeitfrom.com/materialproperties/8011A-O-Aluminum Accessed 1 October 2020.

[18] R.O. Ritchie, A.W. Thompson: Metall Mater Trans A, 16A (1985) 233-248.

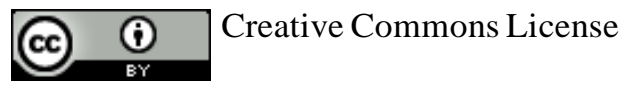

This work is licensed under a Creative Commons Attribution 4.0 International License. 